\title{
Psychometric Properties of the Arabic Version of the Fear of COVID-19 Scale (FCV-19S) Among Jordanian Adults
}

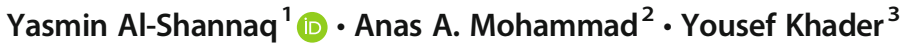

Accepted: 8 June 2021 / Published online: 18 June 2021

(C) The Author(s), under exclusive licence to Springer Science+Business Media, LLC, part of Springer Nature 2021

\begin{abstract}
There is an urgent need to assess the impacts of the Coronavirus-19 disease (COVID-19) outbreak on mental health among the general population such as the Fear of COVID-19. The current study aimed to provide further validation of the Arabic version of the Fear of COVID-19 Scale (FCV-19S) for use among Jordanian adults. A cross-sectional study was conducted using an anonymous online survey between 1 and 12 May 2020. The forward-backward translation method was adopted to translate the FCV-19S into Arabic. The study sample included 725 Jordanian adults. The internal consistency (Cronbach's $\alpha$ ) was 0.91 indicating excellent internal consistency. As for convergent validity, a significant positive correlation was found between the Fear of COVID-19 Scale (FCV-19S) and the three subscales of the Depression, Anxiety, and Stress Scale-21 (DASS-21), with the highest correlation being between the FCV-19S and the anxiety subscale $(r=0.54$, $p<.05)$, followed by the stress subscale $(\mathrm{r}=0.51, \mathrm{p}<.05)$, and lastly, the depression subscale $(r=0.46, p<.05)$. Construct validity was assessed using exploratory factor analysis (EFA), confirmatory factor analysis (CFA), and item response theory (IRT). The unidimensional factor structure of the FCV-19S was confirmed on the study sample. The Arabic version of the FCV-19S is a reliable and valid instrument with good psychometric properties. The use of this scale for assessing the severity of fear related to the COVID-19 pandemic among Arabic-speaking populations is recommended. The findings may guide future COVID-19-related research and further validation testing.
\end{abstract}

Keywords COVID-19 pandemic · Fear ofCOVID-19 · Arabic FCV-19S · Psychometrics · Jordan

After reporting the first COVID-19 case in Jordan on March 3, 2020, the Jordanian government implemented several measures, such as lockdown and quarantine to prevent the spread of COVID-19 and protect the Jordanian population (Alqutob et al., 2020). Such measures and interventions were unexpected and impacted Jordanian people of all ages and of both sexes.

Yasmin Al-Shannaq

ymshannaq@just.edu.jo

Extended author information available on the last page of the article 
The COVID-19 pandemic has caused people to experience feelings of fear, stress, depression, and anxiety (Ahorsu et al., 2020; Bitan et al., 2020; Lin, 2020). COVID-19 has high infection, morbidity, and mortality rates, which creates concerns for many people and puts the mental health of people around the world at risk (Ahorsu et al., 2020; Satici et al., 2020). Fear has been reported as being one of the most common psychological impacts of the outbreak of COVID-19 (Van Bavel et al., 2020). Fear is directly related to its outbreak and nature (Ahorsu et al., 2020; Bitan et al., 2020; Lin, 2020). Fear associated with COVID-19 may include fear of becoming infected, fear of being in contact with individuals who are infected or suspected of infection, and fear of infecting others (Ahorsu et al., 2020; Bitan et al., 2020; Lin, 2020).

The evidence shows that the COVID-19 pandemic has had several psychological impacts on the general population, including depression, anxiety, stress, and fear (Knipe et al., 2020; Rajkumar, 2020; Roy et al., 2020; Wang et al., 2020; Zhang \& Ma, 2020). For example, a study of 263 participants indicated that the participants had experienced mild stressful impacts as a result of the COVID-19 pandemic, while $52.1 \%$ felt horrified by the disease (Zhang \& Ma, 2020). This highlights the need to investigate the psychological impacts of the pandemic in order to determine the required prevention and support services and develop appropriate psychological interventions (Pakpour \& Griffiths, 2020; Satici et al., 2020). Unfortunately, studies in the literature have focused mainly on the diagnosis, treatment, vaccine, and prevention aspects of COVID-19 (Satici et al., 2020; Wang et al., 2020). Meanwhile, little attention has been paid to the psychological impacts of the pandemic, which include fear (Ahorsu et al., 2020; Pakpour \& Griffiths, 2020; Wang et al., 2020).

The majority of studies which have investigated the psychological impacts of COVID-19 have utilized generic/broad self-report measures which assess different aspects related to the pandemic. These measures include the Impact of Event Scale (IES), the 12-item General Health Questionnaire (the GHQ-12), and the Rand 36-Item Health Status Profile (SF-36). These measures are not specific to a single disease such as COVID-19; rather, they can be used among different populations and to assess the impacts of different diseases. Therefore, there was a need for an appropriate assessment tool which evaluates the psychological impacts of the outbreak of COVID-19 and the levels of fear experienced by people during the pandemic (Ahorsu et al., 2020; Bitan et al., 2020; Satici et al., 2020). Consequently, the 7-item Fear of COVID-19 Scale (FCV-19S) was recently developed by Ahorsu et al. (2020). The FCV-19S is a short, self-report, unidimensional questionnaire aimed at assessing the severity of fear experienced by people during the COVID-19 pandemic (Ahorsu et al., 2020). The questionnaire is easy to understand, simple to administer without prior training, and suitable for both genders and all ages (Sakib et al., 2020). Extensive psychometric testing and analysis has been conducted on the FCV-19S in previous studies. The FCV-19S has been translated into several languages and used among speakers of Italian (Soraci et al., 2020), Bangla (Sakib et al., 2020), Turkish (Satici et al., 2020), Hebrew (Bitan et al., 2020), Arabic in Saudi Arabia (Alyami et al., 2020), English in the U.S. (Perz et al., 2020), Russian (Reznik et al., 2020), Spanish (Huarcaya-Victoria et al., 2020), Japanese (Masuyama et al., 2020), Urdu (Mahmood et al., 2020), and others. Satisfactory psychometric properties of the translated versions have been reported. As COVID-19 continues to spread across the world, there is an urgent need to assess and document, through evidence, the psychological impacts of the pandemic. Therefore, the purpose of this study was to provide further validation of the Arabic version of the FCV-19S to assess the fear experienced by the population in Jordan as a result of the COVID-19 pandemic. The validation was done by translating the FCV-19S into Arabic and conducting a psychometric analysis of the Arabic version among the general population in Jordan. This study 
provides preliminary findings that may guide future research and further validation testing. In addition, this study provides a reliable and valid tool which can be used in other Arab countries to assess fear associated with the COVID-19 pandemic.

\section{Methods}

\section{Participants}

A total of 725 respondents participated in this study and completed the online survey, leading to a response rate of $98.5 \%$. The participants' sociodemographic characteristics during the COVID-19 pandemic are presented in Table 1. The mean age of the participants was 33.7 years $(\mathrm{SD}=9.3)$, with ages ranging from 18 to 65 years. Of the 725 participants, $56.4 \%(n=409)$ were female, and $43.6 \%(n=316)$ were male. The majority of the participants were from the North region $(72.3 \%, n=524)$, and $74.3 \%(n=539)$ had an undergraduate degree. Furthermore, the majority of the participants $(67.6 \% ; n=490)$ were married, $205(28.3 \%)$ were single, $15(2.1 \%)$ were divorced, and $15(2.1 \%)$ were widowed. Most of the participants were employed $(69 \%, n=449)$ and had health insurance $(86.1 \% ; n=624)$. Among the participants, $83.7 \%(n=607)$ reported not suffering from any physical illnesses and 92.3\% $(n=669)$ reported not suffering from any mental illnesses. On the other hand, 73.8\% $(n=535)$ of the

Table 1 Sample characteristics

\begin{tabular}{|c|c|c|c|c|c|}
\hline Characteristic & Category & $\mathrm{n}$ & $\%$ & M & SD \\
\hline Age & & & & 33.7 & 9.3 \\
\hline \multirow[t]{2}{*}{ Gender } & Male & 316 & 43.6 & & \\
\hline & Female & 409 & 56.4 & & \\
\hline \multirow[t]{3}{*}{ Region of residence } & North & 524 & 72.3 & & \\
\hline & Center & 156 & 21.5 & & \\
\hline & South & 45 & 6.2 & & \\
\hline \multirow[t]{3}{*}{ Education } & High school and below & 78 & 10.7 & & \\
\hline & Undergraduate degree & 539 & 74.3 & & \\
\hline & Graduate degree & 108 & 14.9 & & \\
\hline \multirow[t]{4}{*}{ Marital status } & Single & 205 & 28.3 & & \\
\hline & Married & 490 & 67.6 & & \\
\hline & Divorced & 15 & 2.1 & & \\
\hline & Widowed & 15 & 2.1 & & \\
\hline \multirow[t]{4}{*}{ Occupation } & Employed & 449 & 62 & & \\
\hline & Unemployed & 128 & 17.7 & & \\
\hline & Retired & 120 & 16.6 & & \\
\hline & Student & 28 & 3.9 & & \\
\hline \multirow[t]{2}{*}{ Health insurance } & Yes & 624 & 86.1 & & \\
\hline & No & 101 & 13.9 & & \\
\hline \multirow[t]{2}{*}{ Chronic physical problems } & Yes & 118 & 16.3 & & \\
\hline & No & 607 & 83.7 & & \\
\hline \multirow[t]{2}{*}{ Family history of chronic physical problems } & Yes & 535 & 73.8 & & \\
\hline & No & 190 & 26.2 & & \\
\hline \multirow[t]{2}{*}{ Mental health problems } & Yes & 56 & 7.7 & & \\
\hline & No & 669 & 92.3 & & \\
\hline \multirow[t]{2}{*}{ Family history of mental health problems } & Yes & 64 & 8.8 & & \\
\hline & No & 661 & 91.2 & & \\
\hline
\end{tabular}


participants reported that they had a positive family history of chronic physical problems, while $91.2 \%(n=661)$ reported not having a positive family history of mental problems (see Table 1).

\section{Measures}

\section{Sociodemographic Data}

Sociodemographic questionnaire was used to collect the sociodemographic and clinical characteristics for the sample. It included age, gender, region of residence, marital status, educational level, occupation, health insurance, medical and mental illness history, and family history of physical and mental illnesses.

\section{The Fear of COVID19 Scale}

The FCV-19S is a unidimensional 7-item scale aimed at assessing the level of fear experienced by people during the COVID-19 pandemic (Ahorsu et al., 2020). The items are scored on a 5point Likert scale categorized as follows: $1=$ strongly disagree; $2=$ disagree; $3=$ neither agree nor disagree; 4=agree; and 5=strongly agree. The total possible score ranges from 7 to 35 , which higher scores indicating greater fear of COVID-19. The FCV-19S is a reliable and valid tool, with internal consistency of 0.82 and good concurrent validity and supported with other measures (Ahorsu et al., 2020).

\section{Depression, Anxiety, and Stress Scale-21 (DASS-21)}

The DASS-21 is a self-report measure aimed at assessing the negative emotional states/ symptoms of depression, anxiety, and stress experienced by respondents in the preceding week (Lovibond \& Lovibond, 1995). The scale consists of 21 items, with 7 items under each of the three subscales (i.e., depression, anxiety, and stress). Items are scored on a 4-point Likert scale ranging from 0 to $3(0=$ Did not apply to me at all, $1=$ Applied to me to some degree, or some of the time, 2 = Applied to me to a considerable degree, or a good part of the time, and 3 $=$ Applied to me very much, or most of the time). A validated Arabic version of the DASS-21 was used in the current study (Al-Modallal, 2012; Hamaideh, 2018). In this study, Cronbach's $\alpha$ for three subscales of DASS-21 were .89 for depression, .89 for anxiety, and .91 for stress.

\section{Arabic Translation}

At the time this study was conducted, no Arabic version of the FCV-19S was available. Thus, the original English version of the FCV-19S was translated into Arabic using the forwardbackward translation method (Beaton et al., 2000). Forward translation into Arabic was performed by one of the bilingual authors of this study. Then, backward translation into English was performed by another bilingual author who was blinded to the original English version. No discrepancies were found between the original English version and the backwardtranslated version. In order to ensure that the final translated version accurately reflected the original English version, the researchers discussed any challenging phrases or ambiguous words or items until an agreement was reached regarding the appropriate translation. Then, the translated version was piloted on 30 participants who were recruited through social networking 
sites (Facebook and WhatsApp) and who represented the target population. This was to ensure cultural adaptability and that the original instructions, items, and scoring materials were clearly expressed and to improve the quality of the translated version prior to testing the psychometric properties of the scale. The pilot test did not reveal any problems in the translated version or any need for changes, indicating that the final Arabic version of the FCV-19S was ready for use (see the Appendix).

\section{Procedures}

The present study adopted a quantitative approach using a cross-sectional design. Data was collected through an anonymous online survey using Google Forms from 1 May to 12 May 2020, during the second month of the outbreak of COVID-19 in Jordan. Approval was obtained from the principal investigator's affiliated university. All Jordanian adults who were aged 18 years or over were eligible to participate in this study. The participants were recruited through social networking sites (Facebook and WhatsApp) and using snowball sampling methods. The Arabic versions of the standardized measures were used to assess the participants' sociodemographic characteristics and their levels of fear, depression, anxiety, and stress. An introductory message which explained the study purpose and procedures and how data would be used was included at the beginning of the online survey. The participants were also informed that their participation was voluntary and that they would not be receiving any compensation for their participation. Informed consent was obtained electronically. After agreeing to participate in the study, the participants were asked to complete and submit only one online self-report survey each. All of the survey questions were mandatory, thus resulting in no missing data.

\section{Data Analysis}

Descriptive statistics, internal consistency, convergent validity, and exploratory factor analysis (EFA) were analyzed using the IBM Statistical Package for the Social Sciences (SPSS) version 25. Descriptive statistics included means, standard deviations, frequencies, and percentages, were used to describe the sample characteristics and the study measures. With regard to reliability, internal consistency was assessed using Cronbach's alpha (recommended value $\alpha \geq 0.70$ ) for the FCV-19S and the three subscales of the DASS-21 (i.e., depression, anxiety, and stress). Convergent validity was assessed using Pearson's correlation coefficient to assess the correlation between the FCV-19S and the three subscales of the DASS-21. Lastly, construct validity was assessed using factor analysis and item response theory (IRT). An exploratory factor analysis (EFA) was conducted to assess the dimensionality of the items of the translated version of the FCV-19S. The Kaiser-Meyer-Olkin (KMO) coefficient and Bartlett's Test of Sphericity were used to assess the factorability of the items, while principle components extraction and direct oblimin rotation (oblique) were used to assess and decide on the numbers of factors. Confirmatory factor analysis (CFA) was also performed to examine the model fit and validate the factor structure of the translated version of the FCV-19S using AMOS software version 21. The model fit was assessed using the goodness of fit index (GFI), chi-square test $(\chi 2)$, degrees of freedom (df), confirmatory fit index (CFI), Tucker-Lewis Index (TLI), and root mean square error of approximation (RMSEA) fit indices. An acceptable model fit should have GFI, CFI, and TLI $\geq .90$, RMSEA $\leq 0.10$, and non-significant chi-square (Browne \& Cudeck, 1993). After assessing the factor structure of the Fear of COVID-19 Scale, 
the item response theory (IRT) was performed using the IRTPROTM software in order to estimate the difficulty and discrimination of the scale items. IRT was conducted using the Graded Response Model (GRM) to describe the IRT parameters by assessing the item characteristic curve (ICC), which is an S-shaped curve and has an $\alpha$ value $>1.0$ for discrimination.

\section{Results}

EFA was performed to assess the construct validity of the FVC-19S. Prior to conducting the EFA, the suitability of the data for factor analysis was assessed. The inter-item correlations ranged from 0.41 to 0.83 (Table 2). Thus, the correlations between the items were moderate to strong positive correlations. The Kaiser-Meyer-Olkin coefficient (KMO) score was 0.88 and Bartlett's sphericity test was significant $\left(\mathrm{x}^{2}=3482.71, p<0.001\right)$, indicating that a factor analysis would be useful with the data. Factor analysis showed that only one factor in the initial solution had an eigenvalue greater than 1 , which explained $65.94 \%$ of the variance in the FVC-19S scores. This finding was confirmed by the Scree plot, which revealed a clear break after the first factor (see Table 2).

Means (M) and standard deviations (SDs) for each item in the FVC-19S, in addition to the factor loadings and item-total correlations of the one-factor model, are presented in Table 3. The total scale score ranged from 7 to 35, with a mean (SD) of 16.74 (6.54). The factor loadings exceeded 0.7 for all items. The skewness and kurtosis statistics were 0.5 and -0.3 , respectively. The floor effect $(8.4 \%)$ and celling effect (1.4\%) were not significant, indicating that the scale was able to discriminate between subjects at either side of the scale. A considerable number of participants scored the minimum score, indicating significant floor effects for all of the individual items. The item-scale correlations ranged from 0.65 to 0.78 , indicating strong correlations between each item and the total score (see Table 3).

CFA analysis was also performed to confirm the unidimensional factor structure of the Arabic version of the FCV19S. CFA with maximum likelihood estimation examined the fit of the model using several fit indices (i.e., $\chi 2$, GFI, CFI, TLI, and RMSEA). The results of three fit models are presented in Table 4. All items had high factor loadings (above 0.6) and were significant $(p<0.001)$ (see Table 4$)$.

The fit indices of the initial model (model 1) before modification were within acceptable levels, except RMSEA was above 0.10 (Table 4). The modification indices and inter-item correlations indicated that the error covariance between item 1 "I am most afraid of coronavirus-19" and item 2 "It makes me uncomfortable to think about coronavirus-19"and between

Table 2 Inter-item correlation matrix

\begin{tabular}{|c|c|c|c|c|c|c|c|}
\hline & Item 1 & Item 2 & Item 3 & Item 4 & Item 5 & Item 6 & Item 7 \\
\hline Item 1 & 1 & $.736 * *$ & $.499 * *$ & $.651 * *$ & $.611 * *$ & $.557 * *$ & $.568 * *$ \\
\hline Item 2 & & 1 & $.411 * *$ & $.532 * *$ & $.591 * *$ & $.459 * *$ & $.462 * *$ \\
\hline Item 3 & & & 1 & $.657 * *$ & $.542 * *$ & $.680 * *$ & $.659 * *$ \\
\hline Item 4 & & & & 1 & $.633 * *$ & $.654 * *$ & $.669 * *$ \\
\hline Item 5 & & & & & 1 & $.589 * *$ & $.627 * *$ \\
\hline Item 6 & & & & & & 1 & $.832 * *$ \\
\hline Item 7 & & & . & & & & 1 \\
\hline
\end{tabular}

**Correlation is significant at the 0.01 level (2-tailed) 
Table 3 Items' statistics of the FVC-19S

\begin{tabular}{lllllllll}
\hline Item & M & SD & Factor loadings & Skewness & Kurtosis & $\begin{array}{l}\text { Floor } \\
\text { effect }(\%)\end{array}$ & $\begin{array}{l}\text { Ceiling } \\
\text { effect }(\%)\end{array}$ & $\begin{array}{l}\text { Corrected item-total } \\
\text { correlation }\end{array}$ \\
\hline 1 & 2.75 & 1.19 & .81 & .09 & -1.07 & 17.1 & 5.9 & .755 \\
2 & 2.98 & 1.21 & .73 & -.27 & -1.17 & 14.9 & 5.9 & .646 \\
3 & 1.94 & 1.04 & .78 & 1.04 & .34 & 42.3 & 2.1 & .696 \\
4 & 2.27 & 1.22 & .85 & .65 & -.72 & 33.9 & 4.7 & .779 \\
5 & 2.63 & 1.21 & .81 & .22 & -1.06 & 21.2 & 5.8 & .734 \\
6 & 2.02 & 1.07 & .85 & .90 & -.02 & 39.4 & 2.2 & .769 \\
7 & 2.16 & 1.13 & .85 & .70 & -.53 & 35.4 & 2.6 & .779 \\
\hline
\end{tabular}

item 6 "I cannot sleep because I am worrying about coronoavirsu-19" and item 7 "My heart races or palpitates when I think about getting coronavirus-19" were found to be correlated to improve the fit indices and decrease RMSEA. The modification results showed that GFI, CFI, and TLI were higher than 0.90 and RMSEA was decreased (not greater than 0.10), with keeping all items of the scale. Thus, the final modified model (model 3) after further modification indicated that all fit indices were improved and within the acceptable limit $[\chi 2(\mathrm{df}=13, n=725)=105.891, p<.05$; GFI $=.96$; CFI $=$ .97 ; TLI $=.95$; RMSEA $=0.10]$ (Fig. 1). The chi-square $p$ value was significant; thus, it was the only fit index that did not support our model fit due to its sensitivity to sample size (Alavi et al., 2020). As a result, other fit indices were considered in CFA and were within the acceptable limit (Alavi et al., 2020; Browne \& Cudeck, 1993). As with regard to the value of the RMSEA index, a similar finding was reported by a recent study conducted in Greece by Tsipropoulou et al. (2020) (see Fig. 1).

In the present study, item response theory (IRT) was also performed to assess the characteristics and validity of the items of the FCV-19S. The IRT results are presented in Fig. 2 and Table 5. The analysis showed all intercept (a) values were higher than 1.0. Therefore, the IRT results revealed that the Arabic version of the FCV-19S had highly discriminant ability and appropriate item difficulty (see Fig. 2 and Table 5).

As with regard to the reliability analysis, internal consistency was performed for a unidimensional model/a one-factor structure. The results indicated Cronbach's alpha was 0.91 . The convergent validity of the FVC-19S was estimated by correlating the FCV-19S with the three subscales of the DASS-21. The Bivariate Pearson correlations are shown in Table 6. The total score of the FCV-19S correlated with the three subscales of the DASS-21, with the highest significant positive correlation being with the anxiety subscale $(\mathrm{r}=0.54, p<.05)$, followed by the stress subscale $(\mathrm{r}=0.51, \mathrm{p}$ $<.05)$, and lastly, the depression subscale $(\mathrm{r}=0.46, \mathrm{p}<.05)$ (see Table 6).

Table 4 The model fit indices of CFA for a one-factor model of the Arabic FCV-19S

\begin{tabular}{lllllll}
\hline Model & X2 & Df & GFI & CFI & TLI & RMSEA \\
\hline Initial model (model 1) & 495.747 & 14 & .820 & .861 & .792 & .218 \\
Modified model (model 2) & 236.299 & 13 & .906 & .939 & .896 & .154 \\
Final modified model (model 3) & 105.891 & 12 & .959 & .973 & .953 & .102 \\
\hline
\end{tabular}




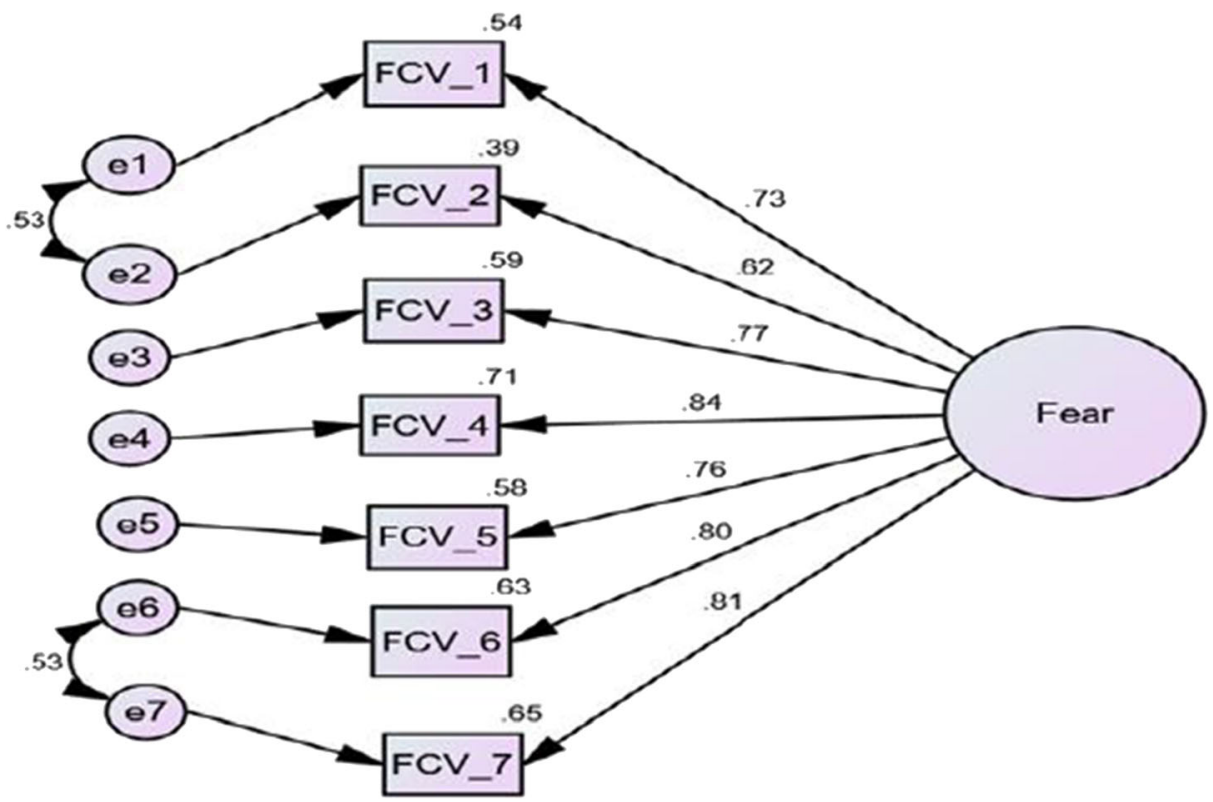

Fig. 1 Final modified model (model 3) with the covariance correlated between item 1 and item 2 and item 6 and item 7 based on standardized estimates

\section{Discussion}

This study evaluated the psychometric properties of the Arabic version of the FCV-19S among a sample of adults in Jordan. The results showed the Arabic version of the scale had excellent internal consistency (as demonstrated by Cronbach's alpha), very good convergent validity (as demonstrated by a significant positive correlation with the three subscales of the DASS-21), and lastly, acceptable construct validity (as demonstrated by the EFA, CFA, and IRT analysis). Based on these results, it is reasonable to conclude that the Arabic version of the FCV-19S is a

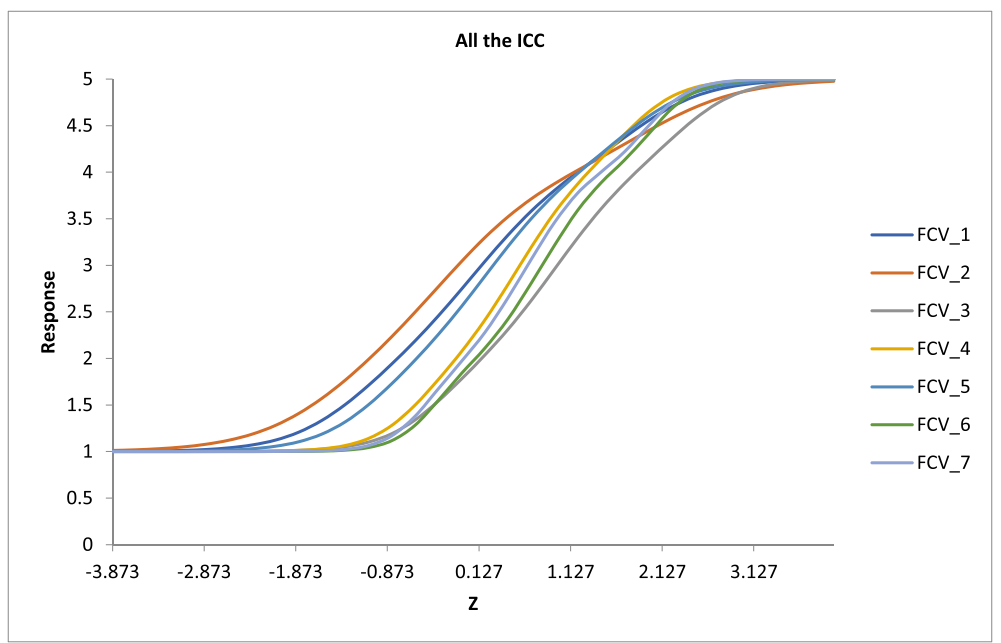

Fig. 2 Items characteristics curve for the FCV-19S 
Table 5 Item response theory estimates for the FCV-19S

\begin{tabular}{lllllll}
\hline Item & Label & $a$ & $b_{1}$ & $b_{2}$ & $b_{3}$ & $b_{4}$ \\
\hline 1 & FCV_1 & 2.33 & -1.14 & -0.09 & 0.55 & 1.94 \\
2 & FCV_2 & 1.87 & -1.38 & -0.33 & 0.18 & 2.13 \\
3 & FCV_3 & 2.82 & -0.20 & 0.79 & 1.37 & 2.44 \\
4 & FCV_4 & 3.24 & -0.41 & 0.44 & 0.90 & 1.87 \\
5 & FCV_5 & 2.56 & -0.89 & 0.07 & 0.65 & 1.89 \\
6 & FCV_6 & 4.18 & -0.25 & 0.64 & 1.19 & 2.15 \\
7 & FCV_7 & 4.17 & -0.35 & 0.49 & 1.02 & 2.08 \\
\hline
\end{tabular}

valid and reliable instrument for assessing the prevalence of fear of COVID-19 among the general population in Jordan. The FCV-19S has been psychometrically evaluated in many countries, and overall, the results of the present study are in line with the results of previous studies.

As with regard to the reliability results, the internal consistency of the Arabic version of the FCV-19S was excellent $(\alpha=.91)$ compared to the findings of other studies. The internal consistency reported in the current study is similar to the results of a study conducted in the United States (U.S.) (Perz et al., 2020), while it is higher than the internal consistency reported in the original study $(\alpha=.82)$ (Ahorsu et al., 2020), in Malaysia $(\alpha=.89)$ (Ping Pang et al., 2020), in Saudi Arabia $(\alpha=.88)$ (Alyami et al., 2020), in Spain $(\alpha=.88)$ (Huarcaya-Victoria et al., 2020), in Italy ( $\alpha=.87$ ) (Soraci et al., 2020), in Bangladesh $(\alpha=.87)$ (Sakib et al., 2020), in Greek $(\alpha=.87)$ (Tsipropoulou et al., 2020), in Israel $(\alpha=.86)$ (Bitan et al., 2020), in Turkey $(\alpha=.85)$ (Satici et al., 2020), in Japan $(\alpha=.82)$ (Masuyama et al., 2020), and lastly, in Pakistan $(\alpha=.85)$ (Mahmood et al., 2020).

As with regard to the convergent validity analysis, the results revealed that fear of COVID-19 had significant positive correlations with depression, anxiety, and stress. These results suggest that people who have higher levels of fear are more likely to report higher levels of depression, anxiety, and stress (Huarcaya-Victoria et al., 2020). This study confirms the findings of other recent studies that found a correlation between FCV-19S and depression, anxiety, and stress (measured using the DASS21) (Bitan et al., 2020; Ping Pang et al., 2020; Satici et al., 2020). The results of this study suggest that the FCV-19S may be used as a tool for assessing the impacts of the COVID-19 pandemic on mental health among different populations. Fear of the COVID-19 may be associated with developing mental illnesses such as depression and

Table 6 Convergent validity of the unidimensional of the FCV-19S correlations with DASS-21 three subscales

\begin{tabular}{lllll}
\hline Measure & 1 & 2 & 3 & 4 \\
\hline 1 FCV-19 total & - & & & \\
2 DASS depression subscale & $0.465 * *$ & - & - & $0.752 * *$ \\
3 DASS anxiety subscale & $0.538 * *$ & $0.840 * *$ & $-812 *$ \\
4 DASS stress subscale & $0.509 * *$ & - \\
\hline
\end{tabular}

**Correlation is significant at the 0.01 level (2-tailed) 
anxiety (Soraci et al., 2020). As this disease continues to spread across the world, people's mental health may be impacted by the constant exposure to news about the pandemic and the concerns about becoming infected, which may increase the levels of fear among the general population (Lin, 2020; Soraci et al., 2020). Our results are in line with previous studies which reported fear as being a negative psychological reaction during other viral epidemics, including SARS (Pappas et al., 2009; Reynolds et al., 2008) and MERS-CoV (Bukhari et al., 2016).

The results of the EFA conducted in the present study revealed that the Arabic version of the FCV-19S had a one-factor structure. The results of the CFA and the IRT confirmed the one-factor model was a good fit, suggesting an acceptable model fit. A one-factor structure was also reported as in the original study (Ahorsu et al., 2020), in Saudi Arabia (Alyami et al., 2020), in Bangladesh (Sakib et al., 2020), in Italy (Soraci et al., 2020), in Turkey (Satici et al., 2020), in the U.S. (Perz et al., 2020), in Greece (Tsipropoulou et al., 2020), in Malaysia (Ping Pang et al., 2020), and in Pakistan (Mahmood et al., 2020). Meanwhile, studies which used Russian version (Reznik et al., 2020), the Hebrew version (Bitan et al., 2020), Spanish version (Huarcaya-Victoria et al., 2020), and Japanese version (Masuyama et al., 2020) suggested a two-factor structure model, including emotional reactions and symptomatic/physiological expressions of fear. Based on the psychometric results, this study confirmed the unidimensionality of the Arabic version of the FCV-19S among a Jordanian adult sample. Therefore, this study concludes that the Arabic version of the FCV-19S is a reliable and valid instrument for assessing the severity of fear of COVID-19 among the general population in Jordan.

The present study has contributed to the available literature by being the first study to use the FCV-19S among the general population in Jordan. In addition, this study provides further evidence for psychometric properties of the Arabic version of the FCV-19S, replicating the psychometric testing done by Alyami et al. (2020) in Saudi Arabia. Moreover, the Arabic version used in this study not only supports another Arabic version but also supports other versions available in Persian (original version; Ahorsu et al., 2020), English (Ahorsu et al., 2020), Italian (Soraci et al., 2020), Bangla (Sakib et al., 2020), Turkish (Satici et al., 2020), Greek (Tsipropoulou et al., 2020), Japanese (Masuyama et al., 2020), Spanish (HuarcayaVictoria et al., 2020), Malay (Ping Pang et al., 2020), and Urdu (Mahmood et al., 2020). This extensive validation research on the FCV-19S will allow researchers to conduct comparative studies on the fear of COVID-19 among different populations at the national and international levels.

\section{Limitations}

The current study has some limitations. First, the study sample only included adults in Jordan, and therefore, the findings may not be generalizable to the elderly population, children, and adolescents in Jordan. Furthermore, psychometrically testing this scale on other Arabic-speaking populations outside Jordan is recommended. Second, the participants' responses to the self-report questionnaire used to assess the fear of COVID-19 may have been influenced by social desirability factors. Third, the use 
of an online survey and snowball sampling methods to collect data during the lockdown period may have led to selection bias, as only adults with access to the internet and the study link had the chance to participate in the study. Forth, as this study used a cross-sectional design, the stability of the scale cannot be examined over time by test-retest reliability. Despite these limitations, the findings indicate that the Arabic version of the Fear of COVID-19 Scale (FCV-19S) is a valid and reliable measurement tool. Consequently, further research and validation testing are needed to confirm the preliminary findings of this study and provide more in-depth data analysis. Future studies conducted on a larger, more representative sample of different populations and ages, studies with a longitudinal design which allows for test-retest reliability, and studies conducted in other Arabic countries are recommended.

\section{Conclusion}

This study provides an evidence that the Arabic version of the Fear of COVID-19 Scale (FCV-19S) is a valid and reliable measurement tool for assessing the severity of fear of COVID-19 among the general population based on the psychometric testing results. Thus, the tool can be used for assessing the psychological impacts of the COVID-19 pandemic on people in Jordan and in other Arabic-speaking countries, allowing mental health professionals to deal more effectively with the mental health problems experienced by people as a result of the pandemic (Bitan et al., 2020; Satici et al., 2020). Mental health professionals can identify the risk groups based on sociodemographic characteristics (Bitan et al., 2020; Pakpour \& Griffiths, 2020) and assess the levels of fear of COVID-19, in addition to other psychological impacts such as panic attack, obsessive compulsive disorder, and stigma, among these risk groups (Satici et al., 2020). This will facilitate the design and development of effective preventive educational interventions for overcoming/alleviating the traumatic effects of COVID-19-related fear as the disease continues to spread (Bitan et al., 2020; Pakpour \& Griffiths, 2020; Satici et al., 2020). In addition, there were no clear polices or protocols aimed at maintaining the psychological well-being of the general population in Jordan during the early stages of the COVID-19 pandemic. In a recent study, religion was the most frequently reported strategy for coping with COVID-19 among a sample of Jordanian adults (Al-Shannaq et al., 2021). In Arab cultures, faith in Allah (God) and carrying out religious activities, such as reciting the Holy Quran and praying, are common strategies used by Arab Muslims to handle many aspects of their lives. In addition, the study participants were staying at home all day during the lockdown (i.e., at the time this study was conducted). Therefore, they were spending time with and caring for their families rather than interacting with others during this unprecedented time (Al-Shannaq et al., 2021; Zhang \& Ma, 2020). Many people may have also relied greatly on the internet and social media during the lockdown to pass time and remain updated with COVID-19-related news and information. As this pandemic continues to spread, the current study stresses the need to develop online education programs aimed at providing suitable psychological support and up-to-date information and news related to COVID-19 (Wang et al., 2020)". 
Appendix. The Arabic version of The Fear of COVID-19 Scale (FCV-19S)

مقياس الخوف من فيروس كورونا_a 19

التعليمات: يرجى وضع دائرة حول الرقم الذي يمثل مدى مو افقتلك أو عدم مو افتتلك على العبار ات التالية فيما يتعلق بالخوف من

فيروس كورونا_q 1:

\begin{tabular}{|c|c|c|c|c|c|c|}
\hline بشدة & أو افق & محايد & $\begin{array}{c}\text { أو افق } \\
\text { أن }\end{array}$ & لا أو افق & & \\
\hline$\circ$ & $\varepsilon$ & $r$ & r & 1 & أنا خائف جداً من فيروس كورونا_9 19 & .1 \\
\hline 0 & $\varepsilon$ & $r$ & r & 1 & أشعر بعدم الارتباح بمجرد التفكير في فيروس كورونا_و19 &.$r$ \\
\hline 0 & $\varepsilon$ & $r$ & $r$ & 1 & تصبح يدي متعرقة عندما أفكر في فيروس كورونا_و 19 &.$r$ \\
\hline$\circ$ & $\varepsilon$ & $r$ & r & 1 & أخاف أن أفقد حياتي بسبب فيروس كورونا_ـ19 &.$\varepsilon$ \\
\hline 0 & $\varepsilon$ & $r$ & r & 1 & 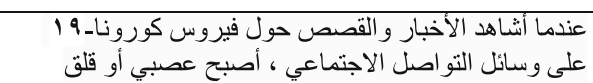 & .0 \\
\hline$\circ$ & $\varepsilon$ & $r$ & r & 1 & لا أسنطيع النوم لأنني قلق بشأن الإصابة بفيروس كورونا_أ19 & .9 \\
\hline 0 & $\varepsilon$ & $r$ & $r$ & 1 & يفيروس قلبي أو تتسار ع دقات قلبي عندما أفكر في الإصابة & .V \\
\hline
\end{tabular}

Author Contribution Yasmin Al-Shannaq contributed to the study conception and design. Material preparation, data collection, and data entry were performed by Yasmin Al-Shannaq and Anas A. Mohammad. Data analysis and interpretations were performed by all authors. The first draft of the manuscript was written by Yasmin Al-Shannaq. All authors commented on previous versions of the manuscript. All authors read and approved the final manuscript.

\section{Declarations}

Ethical Approval All procedures followed were in accordance with the ethical standards of the responsible committee on human experimentation (institutional and national) and with the Helsinki Declaration. The study was approved by the institutional review board of the Jordan University of Science and Technology (No. 100/ 132/2020).

Conflict of Interest The authors declare no competing interests.

Informed Consent Informed consent was electronically obtained from all participants included in the study.

\section{References}

Ahorsu, D. K., Lin, C. Y., Imani, V., Saffari, M., Griffiths, M. D., \& Pakpour, A. H. (2020). The fear of COVID19 scale: Development and initial validation. International Journal of Mental Health and Addiction. https:// doi.org/10.1007/s11469-020-00270-8. 
Alavi, M., Visentin, D. C., Thapa, D. K., Hunt, G. E., Watson, R., \& Cleary, M. (2020). Chi-square for model fit in confirmatory factor analysis. Journal of Advanced Nursing Research, 76(9), 2209-2211. https://doi.org/ 10.1111/jan.14399.

Al-Modallal, H. (2012). Psychological partner violence and women's vulnerability to depression, stress, and anxiety. International Journal of Mental Health Nursing, 21(6), 560-566. https://doi.org/10.1111/j.14470349.2012.00826.x.

Alqutob, R., Al Nsour, M., Tarawneh, M. R., Ajlouni, M., Khader, Y., Aqel, I., et al. (2020). COVID-19 crisis in Jordan: Response, scenarios, strategies, and recommendations. JMIR Public Health and Surveillance, 6(3), e19332. https://doi.org/10.2196/19332.

Al-Shannaq, Y., Mohammad, A. A., \& Aldalaykeh, M. (2021). Depression, coping skills, and quality of life among Jordanian adults during the initial outbreak of COVID-19 pandemic: Cross sectional study. Heliyon, 7, e06873. https://doi.org/10.1016/j.heliyon.2021.e06873.

Alyami, M., Henning, M., Krägeloh, C. U., \& Alyami, H. (2020). Psychometric evaluation of the Arabic version of the Fear of COVID-19 Scale. International Journal of Mental Health and Addiction, 1. https://doi.org/10. 1007/s11469-020-00316-X.

Beaton, D. E., Bombardier, C., Guillemin, F., \& Ferraz, M. B. (2000). Guidelines for the process of cross-cultural adaptation of self-report measures. Spine, 25(24), 3186-3191. https://doi.org/10.1097/00007632200012150-00014.

Bitan, D. T., Grossman-Giron, A., Bloch, Y., Mayer, Y., Shiffman, N., \& Mendlovic, S. (2020). Fear of COVID19 scale: Psychometric characteristics, reliability and validity in the Israeli population. Psychiatry Research, 113100. https://doi.org/10.1016/j.psychres.2020.113100.

Browne, M. W., \& Cudeck, R. (1993). Alternative ways of assessing model fit. In K. A. Bollen \& J. S. Long (Eds.), Testing structural equation models (pp. 136-162). Sage.

Bukhari, E. E., Temsah, M. H., Aleyadhy, A. A., Alrabiaa, A. A., Alhboob, A. A., Jamal, A. A., \& Binsaeed, A. A. (2016). Middle East respiratory syndrome coronavirus (MERS-CoV) outbreak perceptions of risk and stress evaluation in nurses. The Journal of Infection in Developing Countries, 10(08), 845-850. https://doi. org/10.3855/jidc. 6925 .

Hamaideh, S. H. (2018). Alexithymia among Jordanian university students: Its prevalence and correlates with depression, anxiety, stress, and demographics. Perspectives in Psychiatric Care, 54(2), 274-280. https://oi. org/10.1111/ppc.12234.

Huarcaya-Victoria, J., Villarreal-Zegarra, D., Podestà, A., \& Luna-Cuadros, M. A. (2020). Psychometric properties of a Spanish version of the Fear of COVID-19 Scale in general population of Lima, Peru. International Journal of Mental Health and Addiction, 1-14. https://doi.org/10.1007/s11469-020-00354-5.

Knipe, D., Evans, H., Marchant, A., Gunnell, D., \& John, A. (2020). Mapping population mental health concerns related to COVID-19 and the consequences of physical distancing: A Google trends analysis. Wellcome Open Research, 5, 82-92. https://doi.org/10.12688/wellcomeopenres.15870.1.

Lin, C.-Y. (2020). Social reaction toward the 2019 novel coronavirus (COVID-19). Social Health and Behavior, 3(1), 1-2. https://doi.org/10.4103/SHB.SHB_11_20.

Lovibond, P. F., \& Lovibond, S. H. (1995). The structure of negative emotional states: Comparison of the Depression Anxiety Stress Scales (DASS) with the Beck Depression and Anxiety Inventories. Behaviour Research and Therapy, 33, 335-343. https://doi.org/10.1016/0005-7967(94)00075-u.

Mahmood, Q. K., Jafree, S. R., \& Qureshi, W. A. (2020). The psychometric validation of FCV19S in Urdu and socio-demographic association with fear in the people of the Khyber Pakhtunkhwa (KPK) province in Pakistan. International Journal of Mental Health and Addiction, 1-11. https://doi.org/10.1007/s11469-02000371-4.

Masuyama, A., Shinkawa, H., \& Kubo, T. (2020). Validation and psychometric properties of the Japanese version of the fear of COVID-19 scale among adolescents. International Journal of Mental Health and Addiction, 1-11. https://doi.org/10.1007/s11469-020-00368-z.

Pakpour, A. H., \& Griffiths, M. D. (2020). The fear of COVID-19 and its role in preventive behaviors. Journal of Concurrent Disorders, 2(1), 58-63 https://concurrentdisorders.ca/2020/04/03/the-fear-of-covid-19-and-itsrole-in-preventive-behaviors/.

Pang, N. T. P., Kamu, A., Hambali, N. L. B., Mun, H. C., Kassim, M. A., Mohamed, N. H., et al. (2020). Malay Version of the Fear of COVID-19 Scale: Validity and Reliability. International Journal of Mental Health and Addiction, 1-10. https://doi.org/10.1007/s11469-020-00355-4.

Pappas, G., Kiriaze, I. J., Giannakis, P., \& Falagas, M. E. (2009). Psychosocial consequences of infectious diseases. Clinical Microbiology and Infection, 15(8), 743-747. https://doi.org/10.1111/j.1469-0691.2009. 02947.x.

Perz, C. A., Lang, B. A., \& Harrington, R. (2020). Validation of the Fear of COVID-19 Scale in a US college sample. International Journal of Mental Health and Addiction, 1-11. https://doi.org/10.1007/s11469-02000356-3. 
Rajkumar, R. P. (2020). COVID-19 and mental health: A review of the existing literature. Asian Journal of Psychiatry, 52, 102066. https://doi.org/10.1016/j.ajp.2020.102066.

Reynolds, D. L., Garay, J. R., Deamond, S. L., Moran, M. K., Gold, W., \& Styra, R. (2008). Understanding, compliance and psychological impact of the SARS quarantine experience. Epidemiology and Infection, 136(7), 997-1007. https://doi.org/10.1017/S0950268807009156.

Reznik, A., Gritsenko, V., Konstantinov, V., Khamenka, N., \& Isralowitz, R. (2020). COVID-19 fear in Eastern Europe: Validation of the Fear of COVID-19 Scale. International Journal of Mental Health and Addiction, 1. https://doi.org/10.1007/s11469-020-00283-3.

Roy, D., Tripathy, S., Kar, S. K., Sharma, N., Verma, S. K., \& Kaushal, V. (2020). Study of knowledge, attitude, anxiety \& perceived mental healthcare need in Indian population during COVID-19 pandemic. Asian Journal of Psychiatry, 51, 102083. https://doi.org/10.1016/j.ajp.2020.102083.

Sakib, N., Bhuiyan, A. I., Hossain, S., Al Mamun, F., Hosen, I., Abdullah, A. H., et al. (2020). Psychometric validation of the Bangla Fear of COVID-19 Scale: Confirmatory factor analysis and Rasch analysis. International Journal of Mental Health and Addiction. https://doi.org/10.1007/s11469-020-00289-x.

Satici, B., Gocet-Tekin, E., Deniz, M. E., \& Satici, S. A. (2020). Adaptation of the Fear of COVID-19 Scale: Its association with psychological distress and life satisfaction in Turkey. International Journal of Mental Health and Addiction, 1-9. https://doi.org/10.1007/s11469-020-00294-0.

Soraci, P., Ferrari, A., Abbiati, F. A., Del Fante, E., De Pace, R., Urso, A., \& Griffiths, M. D. (2020). Validation and psychometric evaluation of the Italian version of the Fear of COVID-19 Scale. International Journal of Mental Health and Addiction, 1-10. https://doi.org/10.1007/s11469-020-00277-1.

Tsipropoulou, V., Nikopoulou, V. A., Holeva, V., Nasika, Z., Diakogiannis, I., Sakka, S., et al. (2020). Psychometric properties of the Greek version of FCV-19S. International Journal of Mental Health and Addiction, 1. https://doi.org/10.1007/s11469-020-00319-8.

Van Bavel, J. J., Baicker, K., Boggio, P. S., Capraro, V., Cichocka, A., Cikara, M., Crockett, M. J., Crum, A. J., Douglas, K. M., Druckman, J. N., Drury, J., Dube, O., Ellemers, N., Finkel, E. J., Fowler, J. H., Gelfand, M., Han, S., Haslam, S. A., Jetten, J., et al. (2020). Using social and behavioural science to support COVID-19 pandemic response. Nature Human Behaviour, 1-12. https://doi.org/10.1038/s41562-020-0884-z.

Wang, C., Pan, R., Wan, X., Tan, Y., Xu, L., Ho, C. S., \& Ho, R. C. (2020). Immediate psychological responses and associated factors during the initial stage of the 2019 coronavirus disease (COVID-19) epidemic among the general population in China. International Journal of Environmental Research and Public Health, 17(5), E1729. https://doi.org/10.3390/ijerph17051729.

Zhang, Y., \& Ma, Z. F. (2020). Impact of the COVID-19 pandemic on mental health and quality of life among local residents in Liaoning Province, China: A cross-sectional study. International Journal of Environmental Research and Public Health, 17(7), 2381. https://doi.org/10.3390/ijerph17072381.

Publisher's Note Springer Nature remains neutral with regard to jurisdictional claims in published maps and institutional affiliations.

\section{Affiliations}

\section{Yasmin Al-Shannaq ${ }^{1} \cdot$ Anas A. Mohammad ${ }^{2} \cdot$ Yousef Khader $^{3}$}

1 Department of Community and Mental Health Nursing, Faculty of Nursing, Jordan University of Science and Technology, Irbid, Jordan

2 Department of Adult Health Nursing, Faculty of Nursing, Jordan University of Science and Technology, Irbid, Jordan

3 Department of Public Health and Community Medicine, Faculty of Medicine, Jordan University of Science and Technology, Irbid, Jordan 